BENJAMIN, Walter. O capitalismo como religião. São Paulo: Boitempo Editorial, 2013, 192pp.

\title{
Anticapitalismo Religioso: novos textos de Walter Benjamin
}

\author{
Fábio Py Murta de Almeida \\ Faculdade Batista do Rio de Janeiro - Niterói \\ Rio de Janeiro - Brasil
}

O livro O capitalismo como religião é uma obra de quatro mãos, tendo chegado ao público brasileiro em 2013. Não que tenha sido escrito por mais de uma pessoa, afinal, sua autoria é do filósofo judeu-alemão Walter Benjamin, mas sim porque sua edição atual é um esforço editorial do franco-brasileiro Michael Löwy ${ }^{1}$, radicado em Paris como professor da École de Hautes Études em Sciences Sociales (EHESS). Ele organiza a série de escritos avulsos de Benjamin, com o intuito de unir fragmentos de diferentes momentos de sua vida que, em conjunto, mostram o legado anticapitalista do mesmo, até quando assume o limiar místico.

Com o livro em questão, Michael Löwy nos brinda com uma introdução sobre a vida e a obra do filósofo intitulada "Walter Benjamin, crítico da civilização" que, além de apresentar sua biografia, informa o lugar vivencial dos textos se detendo nos interesses expressos em cada fragmento. No exercício explicativo presente no livro, por sua vez, Löwy aponta três eixos temáticos da trajetória intelectual do autor: a questão da prática, o problema da modernidade individualista e a questão do novo romantismo. $\mathrm{O}$ texto que abre essa organização possui o mesmo título do livro: "O capitalismo como religião", quando Benjamin defende o capitalismo como uma religião cultural, uma celebração de um culto sem sonho e sem piedade. Culto este baseado na culpa, transformando-a em universal, pois até a ideia da deidade é expressa por meio do sentimento. Em outras palavras, "o capitalismo é uma religião puramente de culto, desprovida de dogma" e "se desenvolveu como parasita do cristianismo" (:23) - não só demonstrado na base do calvinismo, mas nas tendências cristãs ortodoxas.

O fragmento "Romantismo", de 1913 - produzido por conta de um congresso da juventude -, é voltado à comunidade, à juventude e contra o individualismo moderno. Benjamin conclama os jovens a desistirem do romantismo falso ligado ao indivíduo, pois, para ele, "nada não há de verdadeiro no que nos oferecem de dramas ou heróis da história, de vitórias da técnica e da ciência" (:54). O verdadeiro roman- 
tismo, esquecido pelos jovens, é indefinido, ligado à franqueza, aos nexos espirituais e à história do trabalho.

Em "Drama barroco e tragédia", compara dois estilos artísticos de época: a tragédia e o drama, como o próprio título já diz. Na tragédia, como símbolo de ironia, o herói morre, pois "a morte é a imortalidade irônica; esta é a origem da ironia trágica" (:61). O tempo do drama barroco, por sua vez, é descrito como finito e, praticamente, não-místico. Tais temas são retomados por Walter Benjamin em seu texto "O significado da linguagem no drama barroco e na tragédia", de 1916, onde percebe o trágico como legalidade do discurso oral dos homens a partir do original humano. $\mathrm{Na}$ tragédia, "cada discurso é tragicamente decisivo, palavra por palavra é imediatamente trágica" (:65). Já no drama barroco, o som impregna a obra com dois princípios que o ordenam metafisicamente: a circularidade e a repetição; pois a "música é o círculo do sentimento (...) que destrói a tranquilidade do anseio profundo que dissemina as tristezas da natureza" (:66). O "mundo do drama barroco é um mundo especial que sustenta sua validade grandiosa e equivalente também frente à tragédia" (:67).

Em seguida, tem-se o fragmento "As armas do futuro" (1925), escrito em decorrência dos confrontos ocorridos na I Guerra Mundial, quando se utilizaram armas químicas - das quais as bombas químico-nucleares da segunda grande guerra também fazem parte. Nesse texto, Benjamin critica os métodos químicos, destaca o estado das cidades europeias antes e depois de sua utilização; se antes, nelas, havia "cheiro parecido com o das violetas" (:70), depois, com a utilização das armas químicas, "o ar se tornou sufocante" (:71). Além disso, o autor vislumbra o contrassenso do projeto armamentista das nações destacando que "a França possui hoje pelo menos 2500 aeronaves no serviço ativo que visa à paz" (:70). Para ele, o capitalismo moderno do início do século XX constrói um dilema porque seu projeto de paz se dá por meio de armas bélicas, além da utilização de gases tóxicos, como se pode ver no seguinte excerto: "o gás mostarda corroeu a carne e quando não acarreta diretamente a morte, produz queimaduras cuja cura demanda de três meses" (:71).

Uma vez apresentados os textos supracitados, Benjamin dá espaço aos livros que mais marcaram sua vida até o ano de 1929, por meio do texto "Livros que permanecem vivos". O primeiro livro apresentado é Spatromishe Kunstindustrie, de Alois Riegl, e, nele, a partir do império romano antigo, percebe-se que toda descoberta científica desenrola-se numa revolução procedimental. O segundo é Eisenbauten, de Alfred Gotthold, no qual relaciona a fundição do ferro do século XIX com a história da construção das casas. O terceiro apresentado é a Estrela da Redenção, de Franz Rosenzweig, que traz uma proposta sistemática de teologia judaica a partir da intervenção da dialética hegeliana da obra de Herman Cohen. Por fim, tem-se a História e consciência de classe, de Georg Lukács, obra filosófica coesa ao marxismo, reunindo criticamente a filosofia e a luta de classes na direção de uma revolução concreta.

Em 1929, Walter Benjamin escreve comentários sobre os livros de E.T.A. Hoffmann e Oscar Panizza, autores que se preocupam com o social, o político e o religioso. 
Ele chama Panizza de teólogo, mesmo que tenha cometido ataques radicais à Igreja e ao papado, e que sua posição seja irreconciliável com o ofício teológico como ocorreu com E.T.A. Hoffmann, um artista que "despejava todo seu escárnio e toda sua raiva" (:136). Hoffmann tinha afinidade com romances que giravam em torno do "catolicismo medieval e, sobretudo, do seu complemento: as missas negras, a bruxaria e o satanismo" (:136). Desse modo, Benjamin se mostra interessado por temas de protesto frente às religiões oficiais. Ainda em 1929, o filósofo escreve uma resenha do livro de Marc Brion: Bartolomé de las Casas, onde aponta elementos interessantes sobre o cristianismo da libertação ${ }^{3}$; nele, em vez de o bispo manter o "domínio sobre a Índia" (:171), ele, "se contrapõe aos horrores cometidos em nome do catolicismo" (:172). Nesse ínterim, o filósofo critica as formas estruturais das grandes religiões.

Nos anos subsequentes, entre 1930 e 1931, Walter Benjamin escreve "Crítica Teológica. Sobre Willy Haas, Gestaltender Zeit" desenvolvendo traços de Kafka, Talmude, Kierkegaard, Tomás de Aquino, Pascal e Inácio de Loyola. Apropria-se de Kafka com direito à exegese da sua teologia da fuga, embasado no contexto de uma teologia no romance criminal. Na obra, a teologia tem um sentido pleno, levada pela arte com aspectos destrutivos, quando a iluminação teológica determina tanto a política quanto a economia.

Os últimos quatro artigos da resenha são da década de 1930. O primeiro é do ano de 1931: "Um entusiasta da cátedra: Franz von Baader" na qual escreve sobre Baader e suas conexões com Schelling, caracterizando-o como filósofo da natureza. Para Benjamin, Baader pensava em direção ao infinito com uma máquina elétrica, escolástica e mística. Ele pensava pelo caminho dos românticos, passando pela vida interior com uma nova perspectiva intelectual, se ligando ao espiritualismo extremo para chegar ao estudo do montanhismo. No primeiro momento, apropriava-se das teorias físicas e industriais se aproveitando das elucubrações românticas da natureza para, posteriormente, se envolver com o universalismo romântico contraposto pela atuação congestionada de Goethe. Buscava assim, nas suas intervenções cumprir metas de conciliação das esferas cristãs com as ações místicas; e, politicamente, estava à frente dos contemporâneos vislumbrando a "situação social das classes trabalhadoras" (:140) com o seu romantismo da práxis.

Já em 1937, o filósofo escreve: "Béguin, l'Âme Romantique" enfatizando o romantismo alemão como excelência do gênero. No escrito, busca não perceber as teorias românticas como corretas, mas como histórias que brotam de locais, espaços. Para ele, o romantismo completa um processo que havia sido iniciado em $1800 \mathrm{com}$ a secularização da tradição mística - mesmo que Novallis seja uma dessas afirmativas. Afirma que o período da secularização dessa tradição coincidiu com o desenvolvimento social e industrial que colocou "em cheque a experiência mística perdendo o legado sacramental" (:144).

No ano de 1938, por sua vez, Benjamin produz dois textos: "Instituto Alemão de Livre Pesquisa" e "Crônica dos desempregados alemães". No primeiro, destaca o 
legado interdisciplinar do instituto orientando os trabalhos na direção do desenvolvimento social e de sua teoria. $\mathrm{O}$ instituto lutou contra o positivismo considerando "a sociedade burguesa como eterna e trata suas contradições - tanto teóricas quanto práticas - como bagatela" (:151). Também foi alvo de Frankfurt o pragmatismo americano por sua relação monolítica de teoria e práxis, pois tinha pretensão de avaliar criticamente o conhecimento e a ciência na modernidade. São nesses trabalhos, sobretudo, que ele tece críticas ao conjunto da consciência burguesa, percebendo a figura de Robespierre, a consistência da liderança burguesa. Na qual, o "terror, no fim das contas, adere a esse fantástico; e há um tipo de interiorização que é capaz de se manifestar como crueldade" (:156).

O segundo texto de 1938, último do livro em questão, tem título, "Crônica dos desempregados alemães" discorre sobre o romance Die Rettung, de Anna Seghers. Por ele, Benjamin reconhece que alguns romancistas feriam o privilégio burguês e cita, entre eles, Hamsun que "deixou de lado as 'pessoas simples" (:159), em um período difícil marcado pela grande quantidade de pessoas desempregadas no país. A autora se detém nos proletários que pouco significavam para a época, porque eram implicantes e tinham a iniciativa de viver como as outras pessoas. Por isso, se afastavam deles mesmos, como ocorreu em Findlingen - povoado minerador. Sua esperança estava no jovem Lorentz, desempregado que "deixou, no povoado cinzento, o rastro luminoso que Bentsch jamais esquecerá" (:162). Essa centelha de esperança do relato de Anna Sehers faz dela, aos olhos de Benjamin, a cronista dos desempregados alemães cuja base é a fábula fornecendo ao livro um toque romanesco. Percebe que para se libertarem das amarras político-sociais a aposta de redenção seriam as crianças proletárias por que não seriam "esquecidas tão cedo por nenhum leitor" (:166).

Em resumo, como foi dito, no livro O capitalismo como religião se faz o esforço de revisitar outras fontes da rica e trágica trajetória de Benjamin. Novamente, saúdase o empenho de Michael Löwy em organizar alguns textos outrora inacessíveis, nos quais revelam mais do filósofo rebelde que, já maduro, uniu o marxismo com neoromantismo - do drama, da tragédia, da religião e da magia. Löwy dá "liga" à massa de textos salteados de Benjamin, afinando sua compreensão. É por meio dele que se detalham com mais riqueza a trajetória de formação romântica do autor na década de 1910, sua guinada marxista heterodoxa em 1924 (chamado por Leandro Konder de um marxista melancólico ${ }^{4}$ ), até sua súbita/trágica morte entre a Espanha e a França em 1940.

Espera-se, portanto, que o acesso a esses textos, artigos e resenhas de Walter Benjamin animem tanto o vetor da popularização de suas ideias no Brasil, quanto o vetor acadêmico. Além disso, acredita-se que com a divulgação dessas fontes possam se solidificar novas linhas de pesquisas em suas disciplinas mais prováveis, tais como a Filosofia, a Sociologia e a História; além de também ajudar a depurar a atuação teórico/ prática dos movimentos políticos alternativos, como movimentos sociais, e dos ramos estabelecidos pelo cristianismo heterodoxo da Teologia da Libertação. 


\section{Notas}

1 Nos últimos anos, Michael Löwy vem se dedicando aos estudos de Benjamin, o que pode ser visto nos seguintes trabalhos: LÖWY, Michael. (2002), "A filosofia da história em Walter Benjamin”. Estudos Avançados, v.16, no 45: 199-206; LÖWY, Michael. (2005), Walter Benjamin: aviso de incêndio. Uma Leitura das teses 'Sobre o conceito de história'. São Paulo: Boitempo; LÖWY, Michael. (2012), Judeus heterodoxos.São Paulo: Perspectiva; LÖWY, Michael. (2012), Romantismo e messianismo: ensaios sobre Lukács e Walter Benjamin. São Paulo: Perspectiva.

2 LÖWY, Michael. (2013), "Walter Benjamin: critico da civilização". In W. Benjamin (2013), O capitalismo como religião. São Paulo: Boitempo.

3 Conceito ampliado por Löwy para designar as comunidades cristãs de ontem e de hoje ligadas à ideias e práxis progressistas, vide: LÖWY, Michael. (2000), A guerra dos deuses: religião e política na América Latina. Petrópolis: Vozes.

4 KONDER, Leandro. (1999), Walter Benjamin: o marxismo da melancolia. Rio de Janeiro: Civilização Brasileira. O próprio Michael Löwy indica a nomenclatura "marxismo gótico" a partir do artista surrealista-comunista Andre Breton em: LÖWY, Michael. (2005), Walter Benjamin: aviso de incêndio. Uma Leitura das teses 'Sobre o conceito de história'. São Paulo: Boitempo.

Fábio Py Murta de Almeida (pymurta@gmail.com)

Professor auxiliar de História e Metodologia da Faculdade Batista do Rio de Janeiro (Fabat). Doutorando em Teologia pela PUC-RJ, bolsista sanduíche pelo PSDE-CAPES no École des Hautes Études en Sciences Sociales (EHESS-Paris). Participa do grupo Núcleo de Estudos dos Protestantismos e de suas Teologias (NEPROTES-UFJF/CNPq), do grupo Religião e Mística (UEPA/CNPq) e é coordenador do Centro de Estudos Políticos, Religião e Sociedade (CEPRESUNIFAP/CNPq). 